\title{
Editorial
}

\section{Robyn Zink}

Welcome to the first issue AJOE for 2011, and my first issue as editor. I would like to take this opportunity to thank Glyn Thomas for all of his help in getting this issue of AJOE to you, and to acknowledge the hard work Glyn has put into AJOE over the years. It is a great privilege to take on the role of editor of the journal and I look forward to working with everyone involved in producing this journal, especially the authors and the reviewers. This journal would not exist without the research, the passion and the hard work of the authors, or the time the reviewers give.

AJOE will continue to aim to meet the needs of a wide cross-section of readers and provide clear links between theory, research and practice. Articles on any topic related to the scholarly advancement of outdoor education will be considered for the journal. A new feature that will be included in future issues are abstracts of recently completed Master's and Ph.D theses in topics relevant to outdoor education from Australasia. These are being profiled so readers know what research work is being done in outdoor education at our end of the world, and who some of the emerging researchers are in the field. This work can easily get buried in university libraries and lost to those who could find it interesting and useful.

In this issue it is our pleasure to publish four referred articles and one book review. The issue opens with an article by Glyn Thomas reviewing some recently published outdoor education text books to analyse the degree to which they include material on 'personcentred' facilitation. Given how central facilitation is to outdoor education practice, it is surprising to find how little attention this receives in the text books. Thomas points out that outdoor education textbooks are out of step with teacher education and counsellor education texts in this area. He concludes that this gap deserves attention in the field.

The remaining three articles in this issue are concerned with safety and bring very different lenses to the question of safety practice in the outdoors. Sullivan, Carpenter and Jones examine the talk of New Zealand primary school teachers. They identify three repertoires of safe practice teachers use when they talk about outdoor education. Each repertoire has implications for how they construe learning and good practice in outdoor education.

Boyes and O'Hare use a computer simulation model to explore differences in decision making by experienced outdoor practitioners and less experienced practitioners. They find some marked differences in the sorts of information accessed by the two groups and in the way they organise that information in their decision making processes. The authors suggest the computer simulation tool may be useful in developing inexperienced outdoor practitioners decision making skills.

The final paper in this issue is the fifth in a series by Andrew Brookes analysing fatalities in the outdoors. He extends the scope of his analysis in this paper to include university groups and Australian groups travelling outside of Australia. His findings from these incidents reinforce his previous conclusion that preventing fatal incidents is specific and requires careful understanding of past fatal incidents.

This edition of AJOE concludes with a review of A pedagogy of place: Outdoor education for a changing world by Brian Wattchow and Mike Brown. Finally, a reminder about the 17th National Outdoor Education Conference at the University of Canberra, Australia on the 16-18 of January 2012. The theme for this year's conference is "The next step...Innovations in outdoor education". This conference could be a great way to start next year. A chance to catch up with people, make new connections and be challenged and stimulated by some new ideas.

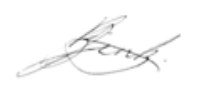

Robyn Zink, Ph.D

Editor 